\title{
РОЛЬ СЕКТОРА ИКТ И ФАКТОРЫ ЦИФРОВОЙ ТРАНСФОРМАЦИИ РЕГИОНАЛЬНОЙ ЭКОНОМИКИ В КОНТЕКСТЕ ГОСУДАРСТВЕННОГО УПРАВЛЕНИЯ
}

\author{
Татьяна Васильевна Миролюбова \\ ORCID ID: 0000-0003-2933-5077, Researcher ID: D-5844-2017, e-mail: mirolubov@list.ru \\ Марина Владимировна Радионова

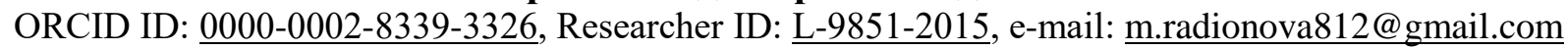

Пермский государственный национальный исследовательский университет

(Россия, 614990, г. Пермь, ул. Букирева, 15)

В России начиная с 2018 г. осуществляется активная государственная политика цифровой трансформации экономики и общества на всех уровнях управления. В основе процессов цифровой трансформации лежит широкое распространение информационно-коммуникационных технологий и возрастание доли этого сектора в экономике. Целью статьи является определение факторов, оказывающих влияние на развитие сектора информационно-коммуникационных технологий экономики региона, для ускорения цифровой трансформации региональной экономической системы посредством инструментов государственного управления. Методологическая база исследования включает теоретические положения в области экономического развития, региональной экономики и государственного управления, затрагивающие процессы цифровой трансформации. Методы исследования - диалектический, структурнологический анализ, метод экспертных оценок, эконометрическое моделирование. Научная новизна исследования состоит в идентификации и обосновании факторных взаимосвязей между развитием сектора ИКТ и процессами цифровой трансформации региональной экономической системы. В ходе исследования выдвинуты и протестированы гипотезы о влиянии различных факторов цифровой трансформации региональной экономики на показатели развития сектора ИКТ экономики региона. В качестве зависимых (управляемых) переменных для построения эконометрических моделей отобраны три показателя, характеризующие развитие сектора ИКТ экономики региона, - численность занятых в секторе ИКТ; объем отгруженных товаров собственного производства, выполненных работ, услуг собственными силами организаций сектора ИКТ; затраты на ИКТ. В соответствии с гипотезой о факторах, влияющих на развитие сектора ИКТ экономики региона, с использованием методики оценки индекса развития ИКТ и применением экспертного подхода определены независимые переменные, характеризующие факторы цифровой трансформации. Согласно результатам эмпирического исследования высокую значимость для развития сектора ИКТ и цифровой экономики в целом имеют факторы, связанные с цифровизацией образования, как в общеобразовательных организациях, так и в организациях среднего профессионального и высшего образования. При этом обязательным требованием цифровой трансформации экономики является развитие инфраструктуры мобильного и широкополосного доступа к сети Интернет. Это требует реализации мер государственной поддержки в отношении инфраструктурных проектов в этой сфере. В целом государственная политика должна сформировать благоприятные условия, при которых будет обеспечиваться, с одной стороны, развитие сектора ИКТ экономики региона, а с другой - рост потребления цифровых продуктов и услуг бизнесом вне сектора ИКТ, населением и организациями бюджетной сферы региона (здравоохранение, образование, социальное обеспечение и защита населения). Перспективы научных исследований лежат в области разработки системы мер государственного воздействия на процессы цифровой трансформации экономики региона в целях повышения уровня конкурентоспособности ее хозяйствующих субъектов.

Ключевые слова: цифровая экономика, цифровая трансформащия, факторь ичифровой трансформации, региональная экономика, конкурентоспособность экономики, сектор информаџионнокоммуникационных технологий, индекс развития ИКТ, государственное управление, эконометрическое моделирование.

(C) Миролюбова Т.В., Радионова М.В., 2020 


\title{
ICT SECTOR ROLE AND DIGITAL TRANSFORMATION FACTORS IN THE REGIONAL ECONOMY IN THE CONTEXT OF PUBLIC GOVERNANCE
}

\author{
Tatyana V. Miroliubova \\ ORCID ID: 0000-0003-2933-5077, Researcher ID: D-5844-2017, e-mail: mirolubov@list.ru \\ Marina V. Radionova \\ ORCID ID: 0000-0002-8339-3326, Researcher ID: L-9851-2015, e-mail: m.radionova812@ gmail.com
}

Perm State University (15, Bukireva st., Perm, 614990, Russia)

\begin{abstract}
Since 2018, Russia has been implementing a dynamic public strategy of digital transformation of the economy and the society at all management levels. Digital transformation is based on a wide penetration of the information and communication technologies and an increased share of this sector in the economy. The purpose of the article is to identify the factors which affect the development of the information and communication technologies sector in the regional economy, boost the digital transformation of the regional economic system with the public management tools. Methodologically, the research includes theoretical aspects in economic development, regional economy and public management, which are connected with the digital transformation. The methods of the research are a dialectic one, structural and logical analysis, expert evaluation method, econometric modeling. Scientific novelty of the research refers to the identification and justification of the factor interconnections between the ICT sector development and digital transformation processes in the regional economic system. The hypotheses about the impact of different factors of the digital transformation on the ICT sector development indicators in the regional economy are proposed and tested. These indicators characterizing the ICT sector development in the regional economy were chosen as the independent (manageable) variables to design the econometric models: the number of the employed in ICT sector; the amount of locally produced and shipped goods, works, services performed with the ICT sector companies' own resources; ICT costs. The independent variables characterizing the factors of the digital transformation are defined under the hypothesis about the factors affecting the ICT sector development in the regional economy, with the evaluation method of the ICT Development Index and an expert approach. The findings of the empirical research show that the factors connected with the education digitalization both in the comprehensive, vocational and higher educational institutions are critically important for the ICT sector development and digital economy on the whole. Along with that, the development of the Internet mobile and wideband access infrastructure is an obligatory requirement for the digital transformation of the economy. This requires the public support measures as regards the infrastructure projects in this area. On the whole, the public policy should provide the favourable conditions which could, on the one hand, develop the ICT sector in the economy of the region, and, on the other hand, induce an increase in the consumption of the digital products and services by the business outside ICT sector, population and budget-dependent companies (health care, education, social services and population rights protection). Further scientific research is seen to be connected with the development of public measures aimed to impact the digital transformation in the economy of the region to boost the competitiveness of the economic entities in the region.

Keywords: digital economy, digital transformation, factors of digital transformation, regional economy, competitiveness of economy, information and communication technologies sector, ICT development index, public management, econometric modeling.
\end{abstract}

\section{Введение}

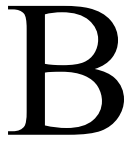

современном мире происходит быстрое распространение информационно-коммуникационных (цифровых) технологий, получившее, по сути, взрывной характер. Переход на цифровые технологии происходит как в масштабе компаний и отраслей, так и в масштабе целых стран. Способность внедрять цифровые технологии напрямую определяет конкурентоспособность и предприятий, и стран. Цифровые технологии вызывают глубокую трансформацию не только во всех сферах экономической дея- тельности, но и в обществе в целом. При этом сами товары и услуги становятся в той или иной степени «цифровыми», возникают и бурно развиваются новые рынки товаров и услуг. Также изменяется и система государственного управления, становясь все более «цифровой». Появился и новый термин «цифровая экономика», а вслед за ним - «цифровая трансформация». Вместе с тем пока данные понятия не имеют устоявшихся значений.

В России на правительственном уровне в 2017 г. была принята программа развития цифровой экономики в стране до 
2024 г., где поставлена задача перехода к такой экономике, «в которой данные в цифровой форме являются ключевым фактором производства» ${ }^{1}$. Постановка этой задачи означает активное государственное управление процессами цифровой трансформации, которые, охватывая экономику, распространяются и на все общество в целом.

Как известно, с позиций менеджмента различают несколько разновидностей направляемого государством развития экономики - трансформацию, модификацию, модернизацию. Трансформация имеет наиболее масштабную форму в силу того, что предполагает кардинальное преобразование сложившейся экономической системы. Таким примером трансформации экономики может служить произошедшая в нашей стране трансформация административнокомандной системы в рыночную.

В силу этого инициатором подобных масштабных преобразований и субъектом управления процессами трансформации является государство. Управляемая государством цифровая трансформация экономики призвана в конечном итоге создать новую структуру экономической системы.

Как указывают Б.Г. Шелегеда, О.Н. Шарнопольская и Н.В. Погоржельская, в современной экономической науке «процессы трансформации экономических систем рассматривались, как правило, под влиянием изменений в методологических подходах к формам, целям, функциям и эффективности структурных преобразований на основе векторов стратегического и оперативного управления, обеспечивающих устойчивый экономический рост и необходимый уровень социальной стабильности» [1].

С нашей точки зрения задача цифровой трансформации, основанной на технологических изменениях, ставится государством впервые. При этом в основе процессов цифровой трансформации лежит

${ }^{1}$ Программа «цфровая экономика Российской Федерации» (утв. Распоряжением Правительства Российской Федерации от 28 июля 2017 г. № 1632). широкое распространение информационно-коммуникационных технологий (далее - ИКТ) и возрастание доли сектора ИКТ в экономике. Под цифровой трансформацией экономики авторы данной статьи понимают процесс интеграции ИКТ во все экономические процессы, требующий внесения принципиальных изменений как в производство существующих, так и создание новых продуктов и услуг, их распределение, обмен и потребление, изменяющий качественные характеристики экономической системы. Иными словами, цифровая трансформация экономики - это не просто процесс внедрения ИКТ, а качественно иное состояние - интеграция ИКТ во все экономические процессы.

Цифровая трансформация невозможна без активного государственного управления. Согласно Д. Норту, «трансформация является функцией не только применяемой технологии, но и институтов» [2]. Государство, как важнейший институт, инициирует все трансформационные изменения. Трансформационными изменениями охватываются субъекты государственного управления, субъекты хозяйствования, домохозяйства, объекты экономической системы, деловая среда, экономические процессы и далее развитие общества в целом.

В связи с вышесказанным целью настоящей статьи является на основе инструментария экономико-математического моделирования определение факторов, оказывающих влияние на развитие сектора ИКТ экономики региона, для ускорения цифровой трансформации региональной экономической системы посредством инструментов государственного управления.

Для достижения данной цели в исследовании тестируются гипотезы о влиянии отобранных факторных показателей цифровой трансформации региональной экономики на показатели развития сектора ИКТ.

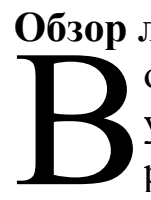

опрос о необходимости государственного управления в рыночной экономике уже давно не является дискуссионным, поскольку в экономической науке устоялась 
идея о необходимости сочетания рыночного саморегулирования и государственного управления. При этом государственное управление играет роль «импульса» для запуска механизма рыночного саморегулирования через применение тех или иных мер и инструментов. Данная идея уже давно является предметом научных дискуссий [3].

Господствующей экономической теорией, обосновывающей формы и масштабы государственного управления экономикой, в XX в. стало кейнсианство [4]. В современной практике государственного управления экономикой, основанной на кейнсианской политике, решающее значение придается именно государственным расходам, которые преследуют две цели: во-первых, они увеличивают спрос со стороны самого государства, во-вторых - создают благоприятные условия для частных инвестиций.

Представляется, что увеличение спроса со стороны государства на цифровизацию прежде всего должно идти через цифровую трансформацию государственного управления, что означает переход «к новым технологиям организации государственного управления и экономики» [5].

Современные подходы к государственному управлению нашли свое отражение в концепции «нового государственного управления» (new public management) $[6 ; 7]$. В этой концепции сделан акцент на применении в государственном управлении управленческих приемов частного бизнеса, на основе которых происходит переход $к$ оказанию государственных услуг как населению, так и бизнесу. В силу этого цифровая трансформация экономики тесным образом связана с «трансформацией государственного управления и построением цифрового правительства. Базой для цифровой трансформации правительства стали достижения стран, построивших открытые электронные правительства и добившихся слаженной работы различных ведомств при предоставлении государственных услуг, а также вовлечении граждан в решение государственных вопросов» [8]. При этом основой успешного функционирования электронного правительства является «формирование единого информационного пространства..., без которого говорить о решении межведомственных задач и предоставлении совместных услуг просто не приходится» [там же].

В свою очередь, «создание единых цифровых информационных платформ и использование сквозных цифровых технологий формируют условия для горизонтальной интеграции и эффективного взаимодействия государственных органов на различных уровнях исполнительной власти, что обеспечит повышение качества государственного управления» [9].

Помимо цифровой трансформации государственного управления, осуществляемой через государственные расходы, необходимо обеспечивать и цифровую трансформацию иных секторов бюджетной сферы - здравоохранения, образования, социальной защиты и др. Кроме цифровой трансформации государственного управления и бюджетной сферы, необходимо решить задачу цифровой трансформации государственного сектора экономики.

Более сложной задачей управляемой государством цифровой трансформации является цифровая трансформация частного сектора экономики. Здесь требуется формирование государством таких условий, при которых цифровая трансформация будет экономически выгодна частному сектору. Представляется, что управленческий механизм в этой области будет работать следующим образом. Первоначально органы государственной власти, применяя определенные методы и инструменты государственного управления, создают импульс для целенаправленных изменений в экономике. Далее в действие вступают рыночные силы, и происходит цепь изменений в экономике, результатом которых становится достижение установленной государством цели. Соответственно, постановка в качестве цели перехода к цифровой экономике означает направленность всех методов и инструментов государственного управления на цифровую трансформацию.

Как известно, существуют следующие основные функции государственного 
управления экономическим развитием: планирование, исполнение, контроль и мониторинг [10]. Постановка цели выступает отправной точкой в планировании и, следовательно, может считаться исходным моментом государственного управления цифровой трансформацией экономики.

Специфика процессов трансформации экономических систем проявляется в таких свойствах, как неустойчивость, нелинейность, переходность, глобальность [11].

Для понимания такой постановки задачи управляемого государством развития российской экономики, как цифровая трансформация, обратимся к проблеме взаимосвязи ИКТ и экономического развития.

Исследованием влияния ИКТ на экономическое развитие занимались многие ученые.

В 80-е гг. ХХ в. нобелевский лауреат Р. Солоу сформулировал так называемый «компьютерный парадокс Солоу»: «Мы видим компьютеры, где угодно, кроме статистики производительности» [12]. Тем самым Р. Солоу определил отсутствие влияния ИКТ на производительность. Однако последующие исследования этого феномена другими учеными опровергли парадокс Р. Солоу, и была выдвинута гипотеза, впоследствии неоднократно подтвержденная, о положительном влиянии ИКТ на производительность, а также о наличии временного лага между внедрением ИКТ и их влиянием на производительность [13-17].

Установлено, что прогрессивное развитие стран и их экономический рост напрямую связаны с информационными технологиями [18].

Дальнейшее экономическое развитие связано с началом развития нового технологического уклада. Составляющий его ядро комплекс информационно-коммуникационных, нано-, биоинженерных и аддитивных технологий растет с темпом около $30 \%$ в год, а его отдельные элементы расширяются с темпом от 20 до 70\% в год [19].

Направляемая государством цифровая трансформация российской экономики на ближайшее время будет связана именно с развитием ИКТ. В связи с этим необходима реализация государством комплекса мер, которые будут способствовать заинтересованности реального сектора экономики в научных разработках в области ИКТ, росту количества высокопроизводительных рабочих мест [20].

В современной России распространение ИКТ и процессы цифровизации региональной экономики происходят при значительном управленческом участии органов государственной власти субъектов РФ посредством цифровизации государственного управления региональным комплексом на основе региональных информационных систем и ресурсов с учетов специфики каждого конкретного региона. В то же время осуществляется интеграция региональных информационных систем с федеральными информационными системами [21]. При этом проблемы государственного регулирования ИКТ являются базовыми в современной теории и практике управления [22].

В связи с этим на уровне регионов необходимо определение направлений государственного регулирования развития ИКТ. По мнению С.В. Баранова и Т.П. Скуфьиной [23], «в территориальном плане остается важным решение проблемы межрегиональной дифференциации по уровню развития ИКТ. Основные меры государственного воздействия должны касаться вопросов: 1) поддержания конкурентной среды среди компаний субъектов РФ, предоставляющих доступ к глобальным информационным сетям; 2) создания условий усиления конкурентной среды в регионах с плохим покрытием и высокой стоимостью услуг сотовой связи; 3) инициации факторов, требующих обучения и переобучения населения и персонала в сфере ИКТ; 4) формирования национальной программной платформы» [23].

Для обоснования перспективных направлений цифровой трансформации региональной экономики посредством инструментов государственного управления далее в исследовании предложена методология идентификации факторов, оказывающих влияние на развитие сектора ИКТ экономики региона. 


\section{Методы и результаты исследования}

$\mathrm{P}$ азвитие сектора ИКТ экономики региона может оцениваться набором показателей прежде всего разработанных и применяемых государственными органами статистики. Для целей управления на региональном уровне отберем ограниченный набор наиболее значимых показателей и определим факторы, влияющие на эти показатели для последующей оценки силы влияния каждого фактора на уровень развития сектора ИКТ экономики региона. Это позволит разработать и применить к выделенным факторам систему государственных мер регулирующего управленческого воздействия, направленных на ускорение развития сектора ИКТ как основы формирования цифровой экономики.

Данное исследование проведено на основе эконометрического моделирования с помощью моделей панельных данных. В этих моделях сформированы два типа переменных - зависимые (управляемые) переменные и независимые. В качестве зависимых (управляемых) переменных моделей были отобраны три показателя, характеризующие развитие сектора ИКТ экономики региона: «численность занятых в секторе ИКТ», «объем отгруженных товаров собственного производства, выполненных работ, услуг собственными силами организаций сектора ИКТ» и «затраты на ИКТ».

Методологической основой для отбора факторов, влияющих на указанные нами зависимые переменные, выступила методика расчета индекса развития ИКТ (ICT Development Index, IDI) ${ }^{1}$.

Индекс развития ИКТ рассчитывается международной организацией International Telecommunication Union (Женева) ${ }^{2}$. Индекс IDI базируется на трех подиндексах:

- подиндекс доступа к ИКТ (ICT Access Sub-index): фиксирует готовность ИКТ и состоит из пяти инфраструктурных индикаторов и показателей доступности

\footnotetext{
${ }^{1}$ Выбор факторных переменных обоснован в статье [24].

${ }^{2}$ ICT Development Index 2017. International Telecommunication Union. URL: https://www.itu.int/net4/ITUD/idi/2017/index.html (дата обращения: 17.10.2019).
}

(численность абонентов фиксированной связи; численность абонентов мобильной связи; международный интернет-трафик на одного пользователя; число домохозяйств, имеющих персональный компьютер; число домохозяйств, имеющих выход в сеть Интернет);

- подиндекс использования ИКТ (ICT Use Sub-index): фиксирует интенсивность ИКТ и состоит из трех индикаторов интенсивности и использования (индивидуальное использование сети Интернет; число абонентов фиксированного широкополосного доступа в Интернет; число абонентов мобильного широкополосного доступа в Интернет);

- подиндекс навыков использования ИКТ (ICT Skills Sub-index): фиксирует способности или навыки как незаменимые входные показатели. Он включает три косвенных показателя (уровень грамотности взрослого населении; общий охват среднего образования; общий охват высшего образования). Данный подиндекс имеет меньший вес в сравнении с двумя предыдущими.

Из числа показателей, используемых при расчете индекса развития ИКТ, на первом этапе исследования с применением экспертного подхода в качестве независимых переменных было отобрано 38 факторных показателей цифровой трансформации экономики, в соответствии с гипотезой о факторах, потенциально влияющих на развитие сектора ИКТ экономики региона.

Три из них - доля организаций, использующих электронную цифровую подпись (\%); удельный вес населения, использующего Интернет для получения государственных и муниципальных услуг в электронной форме, в численности населения в возрасте 15-72 лет, получавшего государственные и муниципальные услуги (\%); удельный вес ИКТ-специалистов высшего уровня квалификации в общей численности занятых (\%) - исключены ввиду недостаточной продолжительности периода наблюдений.

Далее рассчитаны коэффициенты корреляции между оставшимися 35 независимыми переменными и тремя управляемыми (зависимыми) переменными. В качестве базы для проведения исследования 
использованы панельные данные Росстата по регионам РФ за 2015-2017 гг. Расчеты проведены с использованием про- граммного пакета Gretl. Результаты представлены в табл. 1.

\section{Таблица 1. Матрица корреляции для моделирования показателей развития сектора ИКТ и цифровой экономики регионов РФ}

\section{Table 1. Correlation matrix for modeling the development indicators in ICT sector and digital} economy in the $\mathrm{RF}$ regions

\begin{tabular}{|c|c|c|c|}
\hline \multirow{2}{*}{ Независимые переменные } & \multicolumn{3}{|c|}{ Зависимые переменные* } \\
\hline & Y1 & Y2 & Y3 \\
\hline $\begin{array}{l}\text { Число подключённых абонентских устройств мобильной связи на } 1000 \text { чел. } \\
\text { на конец года, штук (X1) }\end{array}$ & 0,4112 & 705 & 3013 \\
\hline Удельный вес домохозяйств, имевших персональный компьютер, \% (X2) & 0,2134 & 0,1857 & 0,2105 \\
\hline Персональных компьютеров на 100 домохозяйств, штук (X3) & 0,2963 & 0,3052 & 0,286 \\
\hline Удельный вес домохозяйств, имевших доступ в Интернет, \% (X4) & 0,1686 & 0,1564 & 0,1681 \\
\hline Удельный вес домохозяйств, имевших широкополосный доступ, \% (X5) & 0,2373 & 0,1902 & 0,1952 \\
\hline Число персональных компьютеров на 100 работников, штук (Х6) & 0,4473 & 0,3897 &, 3411 \\
\hline $\begin{array}{l}\text { Число персональных компьютеров на } 100 \text { работников с доступом в Интернет, } \\
\text { штук (X7) }\end{array}$ & 0,4555 & 0,3801 & 0,3596 \\
\hline $\begin{array}{l}\text { Доля медицинских организаций государственной и муниципальной систем здра- } \\
\text { воохранения (больницы и поликлиники), подключённых к сети Интернет, \% (X8) }\end{array}$ & 0,0521 & 0,0578 & 0,0838 \\
\hline $\begin{array}{l}\text { Доля государственных (муниципальных) образовательных организаций, реали- } \\
\text { зующих программы общего и/или среднего профессионального образования, } \\
\text { подключённых к сети Интернет, \% (X9) }\end{array}$ & 0,4813 & 0,2485 & 0,2725 \\
\hline $\begin{array}{l}\text { Доля органов государственной власти, органов местного самоуправления и гос- } \\
\text { ударственных внебюджетных фондов, подключённых к сети Интернет, \% (X10) }\end{array}$ & 0,4218 & 0,3654 & 0,3105 \\
\hline $\begin{array}{l}\text { Население, использовавшее Интер } \\
\text { в возрасте } 15-72 \text { года) за последни }\end{array}$ & 0,2143 & 0,1837 & 0,2091 \\
\hline $\begin{array}{l}\text { L фиксированного широкополосного } \\
\text { (X12) }\end{array}$ & 0,9535 & 0,8319 & 0,8686 \\
\hline $\begin{array}{l}\text { Число активных абонентов фиксированного широкополосного доступа к сети } \\
\text { Интернет на } 100 \text { чел. населения на конец года, единиц (X13) }\end{array}$ & 0,3778 & 0,3151 & 0,28 \\
\hline $\begin{array}{l}\text { Число активных абонентов мобильного широкополосного доступа к сети } \\
\text { Интернет на } 100 \text { чел. населения на конец года, единиц (X14) }\end{array}$ & 0,2312 & 0,2657 & 0,2839 \\
\hline $\begin{array}{l}\text { Число активных абонентов мобильной связи, использующих услуги доступа } \\
\text { к сети Интернет на конец года, тыс. (X15) }\end{array}$ & 0,9294 & 0,9114 & 0,84 \\
\hline $\begin{array}{lllll}\text { Объём информации, переданной } & \text { от/к } \\
\text { оператора при доступе к сети Интернет, петабайт (X16) } & & & \text { отчитывающегося } \\
\end{array}$ & 0,9487 & 0,9132 & 0,9 \\
\hline $\begin{array}{l}\text { Число активных абонентов - юридических лиц фиксированного широкополосного } \\
\text { доступа к сети Интернет, на конец года, тыс. (X17) }\end{array}$ & 0,926 & 0,8478 & 0,7602 \\
\hline Организации, использовавшие персональные компьютеры, \% (X18) & 0,1192 & 0,1528 & 0,1272 \\
\hline Орган & 0,2378 & 0,2373 & 0,2553 \\
\hline сети, \% (X20) & 0,2619 & 0,2228 & \\
\hline е информационные сети, \% (X21) & 0,2129 & 0,1436 & 0,1488 \\
\hline Организации, использовавшие сеть Интернет, \% (X22) & 0,2135 & 0,1464 & 0,1551 \\
\hline Организации, использовавшие сеть Интернет, широкополосный доступ, \% (X23) & 0,2387 & 0,2112 & 0,2055 \\
\hline щего числа обследованных (X24) & 0,4388 & 0,3647 & 0,3069 \\
\hline программные средства, \% (Х25) & 0,1838 & 0,1986 & 0,1459 \\
\hline Организации, использовавшие электронные системы документооборота, \% (X26) & 0,0447 & 0,0739 & 0,047 \\
\hline $\begin{array}{l}\text { Организации, использовавшие электронный обмен данными между своими и } \\
\text { внешними информационными системами, \% (X27) }\end{array}$ & 01 & 0,1 & 0 , \\
\hline
\end{tabular}




\begin{tabular}{|c|c|c|c|}
\hline \multirow{2}{*}{ Независимые переменные } & \multicolumn{3}{|c|}{ Зависимые переменные* } \\
\hline & Y1 & Y2 & Y3 \\
\hline $\begin{array}{l}\text { Удельный вес организаций (в общем числе организаций предпринимательского } \\
\text { сектора), использующих «облачные сервисы», \% (X28) }\end{array}$ & 0,3304 & 0,3122 & 0,3163 \\
\hline $\begin{array}{lcccc}\text { Число персональных } & \text { компьютеров, } & \text { используемых } & \text { в учебных целях, } \\
\text { в государственных и } & \text { муниципальных } & \text { организациях } & \text { (общеобразовательные } \\
\text { организации) на } 1000 \text { обучающихся (X29) } & & & \\
\end{array}$ & 0,1454 & 0,1695 & 0,2007 \\
\hline 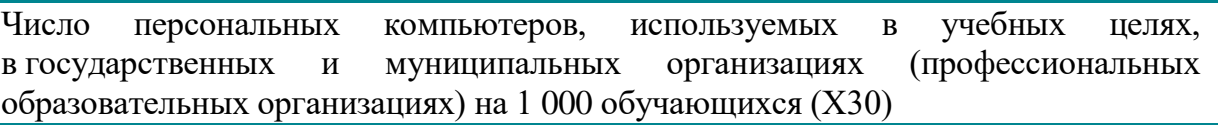 & 0,1444 & 0,2019 & 0,2006 \\
\hline 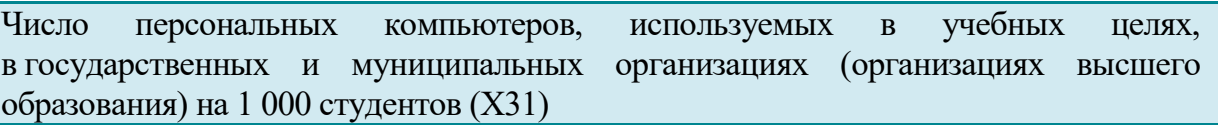 & $-0,0012$ & 0,0172 & 0,0526 \\
\hline $\begin{array}{l}\text { Доля занятого населения в возрасте 15-72 лет с высшим образованием, } \\
\text { \% к итогу (Х34) }\end{array}$ & 0,3903 & 0,4003 & 0,3136 \\
\hline $\begin{array}{l}\text { Доля занятого населения в возрасте } 15-72 \text { лет со средним образованием, } \\
\text { \% к итогу (Х35) }\end{array}$ & 0,0148 & 0,0264 & 0,0741 \\
\hline $\begin{array}{l}\text { Удельный вес населения, использующего Интернет для заказа товаров, услуг, в } \\
\text { общей численности населения в возрасте } 15-74 \text { лет, \% (X36) }\end{array}$ & 0,2003 & 0,2244 & 0,2221 \\
\hline  & 0,2008 & 0,1127 & 0,1566 \\
\hline
\end{tabular}

В данном исследовании в качестве зависимых переменных были выбраны «численность занятых в секторе ИКТ», «объем отгруженных товаров собственного производства, выполненных работ, услуг собственными силами организаций сектора ИКТ», «затраты на ИКТ» для регионов РФ. Поскольку рассмотренные данные имеют панельную структуру, то такие данные позволяют проследить индивидуальные эффекты объектов во временном разрезе [25; 26].

Для идентификации факторов, оказывающих влияние на развитие сектора ИКТ экономики региона, было рассмотрено несколько спецификаций моделей на панельных данных, а именно линейные модели с зависимой переменной; логарифмические модели с логарифмом зависимой переменной и логарифмами факторных признаков. Методом пошаговой регрессии были отобраны модели со значимыми переменными. Разные спецификации моделей сравнивались между собой по информационному критерию Шварца, который принимает наименьшее значение для наилучшей модели [27]. Среди рассмотренных спецификаций первая оказалась наиболее приемлемой по критерию Шварца.

Напомним, что модели со случайными эффектами используются, когда объекты выбираются случайным образом из большой генеральной совокупности элементов. Модель с фиксированными эффектами предполагает, что индивидуальный эффект может быть коррелирован с переменными. Как подчеркивает J.M. Wooldridge [28], смысл фиксированного эффекта заключается в том, чтобы отразить влияние пропущенных или ненаблюдаемых переменных, характеризующих индивидуальные особенности исследуемых объектов, не меняющиеся со временем. Также были построены модели с включенными временными эффектами (time fixed effect) в виде фиктивных переменных [25].

Следующим этапом стало сравнение построенных моделей между собой и выбор наиболее адекватной модели.

Для выбора между моделью с фиксированными и случайными эффектами использовался статистический критерий Хаусмана, нулевая гипотеза которого гласит, что индивидуальные эффекты могут 
быть случайными, т. е. модель со случайными эффектами предпочтительнее [28; 29].

Для выбора между моделью со случайными эффектами и pooled-моделью применяется критерий Бройша - Пагана, нулевая гипотеза которого говорит о том, что дисперсия случайных эффектов равна нулю [27], т. е. модель pooled является наилучшей.

Для сравнения обобщённой модели с моделью с фиксированными эффектами применяют робастный критерий Фишера (robust test for differing group intercepts), для которого нулевая гипотеза соответствует выбору pooled-модели против модели с фиксированными эффектами [28; 29].

Таблица 2. Моделирование влияния факторов цифровой трансформации на численность занятых в секторе ИКТ экономики регионов РФ

Table 2. Modeling of the impact of the digital transformation factors on the number of the employed in ICT sector in the RF regions' economy

\begin{tabular}{|c|c|c|c|c|c|c|}
\hline \multirow{2}{*}{ Переменная } & \multicolumn{2}{|c|}{$\begin{array}{c}\text { Объединенная (pooled) } \\
\text { модель }\end{array}$} & \multicolumn{2}{|c|}{$\begin{array}{c}\text { Модель с фиксированными } \\
\text { эффектами }\end{array}$} & \multicolumn{2}{|c|}{$\begin{array}{c}\text { Модель со случайными } \\
\text { эффектами }\end{array}$} \\
\hline & Коэффициент & \begin{tabular}{|c|} 
Стандартная \\
ошибка
\end{tabular} & Коэффициент & $\begin{array}{c}\text { Стандартная } \\
\text { ошибка }\end{array}$ & Коэффициент & $\begin{array}{c}\text { Стандартная } \\
\text { ошибка }\end{array}$ \\
\hline const & $37,5642 * *$ & 17,9399 & $36,9702 * *$ & 13,5865 & $36,6930 * * *$ & 13,8831 \\
\hline $\mathrm{X} 1$ & 0,0039 & 0,0025 & 0,0054 & 0,0045 & 0,0047 & 0,0039 \\
\hline $\mathrm{X} 4$ & $-0,3193 * * *$ & 0,08651 & $-0,3451 * * *$ & 0,904 & $-0,3311 * * *$ & 0,07687 \\
\hline X6 & $0,2673 * *$ & 0,1161 & 0,2437 & 0,1506 & $0,2598 *$ & 0,1442 \\
\hline $\mathrm{X} 8$ & $-0,3351 * *$ & 0,1368 & $-0,3406 * * *$ & 0,0772 & $-0,3374 * * *$ & 0,0841 \\
\hline $\mathrm{X} 9$ & $-0,0090 * * *$ & 0,0028 & $-0,0094 * * *$ & 0,0024 & $-0,0091 * * *$ & 0,0023 \\
\hline $\mathrm{X} 12$ & $0,0418 * * *$ & 0,0066 & $0,0423 * * *$ & 0,0030 & $0,0420 * * *$ & 0,0034 \\
\hline $\mathrm{X} 14$ & $-0,1562 * * *$ & 0,04552 & $-0,2006 * *$ & 0,0779 & $-0,1796 * *$ & 0,0708 \\
\hline $\mathrm{X} 15$ & $5,68 * 10^{-6} * * *$ & $1,56 * 10^{-6}$ & $5,998 * 10^{-6} * * *$ & $1,51 * 10^{-6}$ & $5,87 * 10^{-6} * * *$ & $1,44 * 10^{-6}$ \\
\hline $\mathrm{X} 16$ & $6,91 * 10^{-9} *$ & $3,96 * 10^{-9}$ & $6,73 * 10^{-9} * *$ & $2,61 * 10^{-9}$ & $6,78 * 10^{-9} * *$ & $2,68 * 10^{-9}$ \\
\hline $\mathrm{X} 17$ & $-1,34 * 10^{-5} * *$ & $6,44 * 10^{-6}$ & $-1,45^{*} 10^{-5}$ & $8,64 * 10^{-6}$ & $-1,41 * 10^{-5} *$ & $8,54 * 10^{-6}$ \\
\hline X19 & $-0,2971 * * *$ & 0,0943 & $-0,3068 * *$ & 0,0905 & $-0,2989 * * *$ & 0,0931 \\
\hline $\mathrm{X} 20$ & 0,1431 & 0,0956 & 0,1153 & 0,0785 & 0,1248 & 0,0818 \\
\hline $\mathrm{X} 22$ & $0,3311 * * *$ & 0,1192 & $0,4119 * *$ & 0,1365 & $0,3781 * * *$ & 0,1097 \\
\hline $\mathrm{X} 27$ & $-0,1837^{*}$ & 0,0961 & $-0,2068 *$ & 0,1002 & $-0,2011 * *$ & 0,0874 \\
\hline $\mathrm{X} 29$ & $0,0173 *$ & 0,0096 & 0,0189 & 0,0137 & 0,0179 & 0,0148 \\
\hline $\mathrm{X} 35$ & $-0,1453$ & 0,0907 & $-0,1350 *$ & 0,0623 & $-0,1371 * *$ & 0,0662 \\
\hline $\begin{array}{l}\text { Критерий } \\
\text { Шварца }\end{array}$ & \multicolumn{2}{|c|}{502,49} & \multicolumn{2}{|c|}{530,46} & \multicolumn{2}{|c|}{505,36} \\
\hline \multicolumn{3}{|c|}{$\begin{array}{c}\text { Статистика теста Хаусмана } \\
\text { (Hausman) }\end{array}$} & $1,42 * 10^{-16}$ & \multicolumn{2}{|c|}{ p-value. Hausman } & 0,00 \\
\hline \multicolumn{3}{|c|}{$\begin{array}{c}\text { Статистика Бройша - Пагана } \\
\text { (Breusch - Pagan) }\end{array}$} & 1,6804 & \multicolumn{2}{|c|}{$\begin{array}{c}\text { p-value. } \\
\text { Breusch - Pagan }\end{array}$} & 0,1951 \\
\hline \multicolumn{3}{|c|}{$\begin{array}{c}\text { Статистика теста } \\
\text { (Robust test for differing group intercepts) }\end{array}$} & 0,3666 & \multicolumn{2}{|c|}{$\begin{array}{l}\text { p-value. } \\
\text { Robust test }\end{array}$} & 0,9164 \\
\hline
\end{tabular}

Примечание: ***, **, *- значимость на $1 \%, 5$ и и $10 \%$-ном уровне соответственно.
Также были рассмотрены модели с фиксированными и случайными эффектами с включенными временными эффектами. Наличие таких эффектов в моделях панельных данных проверялось с помощью критерия Вальда [28].

Далее представим рассчитанные нами параметры моделей для показателей «численность занятых в секторе ИКТ» (табл. 2), «затраты на ИКТ» (табл. 3), «объем отгруженных товаров собственного производства, выполненных работ, услуг собственными силами организаций сектора ИКТ» (табл. 4) для регионов РФ. 


\section{Таблица 3. Моделирование влияния факторов цифровой трансформации на затраты на ИКТ в экономике регионов РФ}

Table 3. Modeling of the impact of the digital transformation factors on the costs in ICT in the $\mathrm{RF}$ regions' economy

\begin{tabular}{|c|c|c|c|c|c|c|}
\hline \multirow{2}{*}{ Переменная } & \multicolumn{2}{|c|}{$\begin{array}{c}\text { Объединенная (pooled) } \\
\text { модель }\end{array}$} & \multicolumn{2}{|c|}{$\begin{array}{c}\text { Модель с фиксированными } \\
\text { эффектами }\end{array}$} & \multicolumn{2}{|c|}{$\begin{array}{c}\text { Модель со случайными } \\
\text { эффектами }\end{array}$} \\
\hline & Коэффициент & $\begin{array}{c}\text { Стандартная } \\
\text { ошибка }\end{array}$ & Коэффициент & $\begin{array}{c}\text { Стандартная } \\
\text { ошибка }\end{array}$ & Коэффициент & $\begin{array}{c}\text { Стандартная } \\
\text { ошибка }\end{array}$ \\
\hline const & $-89016 * * *$ & 32132,1 & $-88606,5 * * *$ & 33263,0 & $-89001,8 * * *$ & 31739,7 \\
\hline $\mathrm{X} 1$ & $-9,12019 * *$ & 4,21798 & $-5,8349$ & 4,6577 & $-7,2446^{*}$ & 4,3218 \\
\hline X3 & $136,376 * * *$ & 41,9126 & $119,152 * *$ & 44,8705 & $126,563 * * *$ & 42,1693 \\
\hline $\mathrm{X} 8$ & $422,655^{*}$ & 250,918 & 342,376 & 259,2151 & 376,599 & 247,4530 \\
\hline $\mathrm{X} 9$ & $-35,4217 * * *$ & 3,4266 & $-37,174 * * *$ & 3,7171 & $-36,4783 * * *$ & 3,4753 \\
\hline $\mathrm{X} 12$ & $92,2374 * * *$ & 7,43262 & $92,189 * * *$ & 7,6125 & $92,2651 * * *$ & 7,2962 \\
\hline $\mathrm{X} 14$ & $-185,532 * *$ & 71,2527 & $-207,705 * *$ & 88,3248 & $-194,960 * *$ & 76,5758 \\
\hline $\mathrm{X} 15$ & $0,026^{* * *}$ & 0,0017 & $0,0273 * * *$ & 0,0018 & $0,0269 * * *$ & 0,0017 \\
\hline $\mathrm{X} 17$ & $-0,1011 * * *$ & 0,0096 & $-0,1049 * * *$ & 0,0100 & $-0,1034 * * *$ & 0,0095 \\
\hline X19 & $-383,465 * *$ & 165,151 & $-440,291 * *$ & 172,6460 & $-418,949 * *$ & 164,0470 \\
\hline $\mathrm{X} 21$ & $2361,14 * *$ & 1131,97 & $2409,23 *$ & 1264,4200 & $2402,80 * *$ & 1169,5400 \\
\hline $\mathrm{X} 22$ & $-1605,32$ & 1118,48 & $-1559,20$ & 1245,4200 & $-1593,77$ & 1152,9500 \\
\hline $\mathrm{X} 24$ & $-388,33^{* *}$ & 163,565 & $-351,756^{* *}$ & 175,3521 & $-364,693 * *$ & 165,0851 \\
\hline $\mathrm{X} 29$ & $116,461 * * *$ & 16,7539 & $113,435 * * *$ & 17,8551 & $114,693 * *$ & 16,8181 \\
\hline X34 & 329,313 & 230,684 & $300,356 * * *$ & 250,1401 & 311,866 & 233,9650 \\
\hline $\begin{array}{l}\text { Критерий } \\
\text { Шварца }\end{array}$ & \multicolumn{2}{|c|}{1688,915} & \multicolumn{2}{|c|}{1712,013} & \multicolumn{2}{|c|}{1689,866} \\
\hline \multicolumn{3}{|c|}{$\begin{array}{c}\text { Статистика теста Хаусмана } \\
\text { (Hausman) }\end{array}$} & 3,2826 & \multicolumn{2}{|c|}{ p-value. Hausman } & 0,8577 \\
\hline \multicolumn{3}{|c|}{$\begin{array}{c}\text { Статистика Бройша - Пагана } \\
\text { (Breusch - Pagan) }\end{array}$} & 0,2355 & \multicolumn{2}{|c|}{$\begin{array}{c}\text { p-value. } \\
\text { Breusch - Pagan }\end{array}$} & 0,6275 \\
\hline \multicolumn{3}{|c|}{$\begin{array}{c}\text { Статистика теста } \\
\text { (Robust test for differing group intercepts) }\end{array}$} & 0,8828 & \multicolumn{2}{|c|}{$\begin{array}{l}\text { p-value. } \\
\text { Robust test }\end{array}$} & 0,5275 \\
\hline
\end{tabular}

Примечание: $* * *, * *, *-$ - значимость на $1 \%, 5$ \% и 10 \%-ном уровне соответственно.

Согласно табл. 2, по критерию Хаусмана лучшей моделью является модель с фиксированными эффектами, по критерию Фишера и Бройша - Пагана - объединенная модель. Также были рассмотрены модели с включенными временными эффектами, но по критерию Вальда гипотеза об отсутствии временных фиксированных эффектов не была отвергнута.

Анализ данных таблицы 3 показал, что наилучшей моделью также является объединенная модель без временных эффектов.
В таблице 4 представлены результаты моделирования для логарифма модели по зависимой переменной «объем отгруженных товаров собственного производства, выполненных работ, услуг собственными силами организаций сектора ИКТ».

Согласно табл. 4, также по критерию Хаусмана лучшей моделью является модель с фиксированными эффектами, по критерию Фишера и Бройша - Пагана объединенная модель. 
Таблица 4. Моделирование влияния факторов цифровой трансформации на объем отгруженных товаров собственного производства, выполненных работ, услуг собственными силами организаций сектора ИКТ в экономике регионов РФ

Table 4. Modeling of the impact of the digital transformation factors on the amount of the locally produced and shipped goods, works, services performed by the ICT sector companies' own resources in the $R F$ regions' economy

\begin{tabular}{|c|c|c|c|c|c|c|}
\hline \multirow{2}{*}{ Переменная } & \multicolumn{2}{|c|}{$\begin{array}{c}\text { Объединенная (pooled) } \\
\text { модель }\end{array}$} & \multicolumn{2}{|c|}{$\begin{array}{c}\text { Модель с фиксированными } \\
\text { эффектами }\end{array}$} & \multicolumn{2}{|c|}{$\begin{array}{c}\text { Модель со случайными } \\
\text { эффектами }\end{array}$} \\
\hline & Коэффициент & $\begin{array}{c}\text { Стандартная } \\
\text { ошибка }\end{array}$ & Коэффициент & $\begin{array}{c}\text { Стандартная } \\
\text { ошибка }\end{array}$ & Коэффициент & $\begin{array}{c}\text { Стандартная } \\
\text { ошибка }\end{array}$ \\
\hline const & $28,0408 * * *$ & 4,1772 & $29,5309 * * *$ & 4,3196 & $29,0804 * * *$ & 4,1186 \\
\hline $\mathrm{X} 1$ & $0,0032 * * *$ & 0,0009 & $0,0035 * * *$ & 0,0011 & $0,0034 * * *$ & 0,0009 \\
\hline X9 & $0,0018 * *$ & 0,0007 & $0,0014^{*}$ & 0,0008 & $0,0015^{* *}$ & 0,0007 \\
\hline $\mathrm{X} 11$ & $-0,0877 * *$ & 0,0409 & $-0,0789 *$ & 0,0431 & $-0,0829 *$ & 0,0407 \\
\hline $\mathrm{X} 14$ & $-0,0407 * *$ & 0,0158 & $-0,0314$ & 0,0197 & $-0,0353 * * *$ & 0,0171 \\
\hline $\mathrm{X} 17$ & $2,11 * 10^{-6} * * *$ & $6,45 * 10^{-7}$ & $2,47 * 10^{-6} * * *$ & $6,55 * 10^{-7}$ & $2,34 * 10^{-6} * * *$ & $3,27 * 10^{-7}$ \\
\hline $\mathrm{X} 21$ & $-0,2399 * *$ & 0,1020 & $-0,3065^{* * *}$ & 0,1113 & $-0,2845^{* * *}$ & 0,1039 \\
\hline $\mathrm{X} 24$ & $0,1275 * * *$ & 0,0412 & $0,1167 * * *$ & 0,0417 & $0,1197 * * *$ & 0,0399 \\
\hline $\mathrm{X} 25$ & $0,2565 * *$ & 0,1039 & $0,3237 * * *$ & 0,1126 & $0,3017 * * *$ & 0,1056 \\
\hline $\mathrm{X} 26$ & $-0,1854 * * *$ & 0,0509 & $-0,2051 * * *$ & 0,0522 & $-0,1987 * * *$ & 0,0498 \\
\hline $\mathrm{X} 28$ & $0,0952 * *$ & 0,0461 & $0,1313 * * *$ & 0,0479 & $0,1204 * * *$ & 0,0454 \\
\hline X34 & $-0,2288 * * *$ & 0,0566 & $-0,2909 * * *$ & 0,0606 & $-0,2698 * * *$ & 0,0569 \\
\hline $\begin{array}{l}\text { Критерий } \\
\text { Шварца }\end{array}$ & \multicolumn{2}{|c|}{333,687} & \multicolumn{2}{|c|}{351,234} & \multicolumn{2}{|c|}{335,241} \\
\hline \multicolumn{3}{|c|}{$\begin{array}{c}\text { Статистика теста Хаусмана } \\
\text { (Hausman) }\end{array}$} & 199,628 & \multicolumn{2}{|c|}{ p-value. Hausman } & 0,0001 \\
\hline \multicolumn{3}{|c|}{$\begin{array}{c}\text { Статистика Бройша - Пагана } \\
\text { (Breusch - Pagan) }\end{array}$} & 0,27121 & \multicolumn{2}{|c|}{$\begin{array}{c}\text { p-value. } \\
\text { Breusch - Pagan }\end{array}$} & 0,3987 \\
\hline \multicolumn{3}{|c|}{$\begin{array}{c}\text { Статистика теста } \\
\text { (Robust test for differing group intercepts) }\end{array}$} & 1,0875 & \multicolumn{2}{|c|}{$\begin{array}{c}\text { p-value. } \\
\text { Robust test }\end{array}$} & 0,3907 \\
\hline
\end{tabular}

Примечание: ***, **, *- значимость на $1 \%, 5$ \% и $10 \%$-м уровне соответственно.

Моделирование динамики развития сектора ИКТ экономики регионов России на основе определения факторов для ключевых показателей сектора ИКТ на основе моделей панельных данных выявило следующие зависимости.

Численность занятых в секторе ИКТ регионов определяется долей персональных компьютеров на 100 работников, числом активных абонентов - физических лиц фиксированного широкополосного доступа к сети Интернет, долей организаций, использовавших сеть Интернет и серверы, и числом активных абонентов мобильного широкополосного доступа к сети Интернет в регионе на 100 чел. населения, долей занятого населениям в возрасте 15-72 лет со средним образованием, а также числом персональных компьютеров, используемых в учебных целях в государственных и муниципальных общеобразовательных организациях региона на 1000 обучающихся.

Объем отгруженных товаров, работ и услуг в секторе ИКТ экономики региона зависит от доли занятого населениям в возрасте 15-72 лет с высшим образованием, числом подключённых абонентских устройств мобильной связи на 1000 чел. населения, доли государственных (муниципальных) образовательных организаций, реализующих образовательные программы общего и/или среднего образования, а также доли организаций, использующих вебсайты, специальные программные средства и электронные системы документооборота.

Затраты на ИКТ определяются такими основными факторами, как количество персональных компьютеров на 100 домохозяйств, доля организаций, использовавших глобальные информационные 
сети, число активных абонентов мобильной связи, использующих услуги доступа к сети Интернет и число персональных компьютеров, используемых в учебных целях, в государственных и муниципальных организациях (общеобразовательные организации) на 1000 и доля организаций, использовавших серверы.

Опираясь на мнение экспертов, мы пришли к выводу, что использование серверов организациями отражает интенсивность применения таких технологий и программных продуктов, которые сопряжены с высокими затратами.

Таким образом, построенные модели показывают высокую значимость в развитии сектора ИКТ факторов, связанных с цифровизацией образования как в общеобразовательных организациях, так и в организациях среднего профессионального и высшего образования. Обязательным условием цифровой трансформации экономики при этом является развитие инфраструктуры доступа к сети Интернет (как широкополосного, так и мобильного).

\begin{tabular}{|c|c|c|}
\hline Ha & авления & государственной \\
\hline $\begin{array}{l}\text { политики } \\
\text { экономик }\end{array}$ & $\begin{array}{l}\text { развития } \\
\text { региона }\end{array}$ & сектора \\
\hline
\end{tabular}
которые органы государственной власти региона могут ускорить развитие сектора ИКТ экономики региона и тем самым обеспечить цифровую трансформацию региональной экономики и ее преобразование в цифровую экономику. В целом государственная политика должна создать благоприятные условия, при которых обеспечивались бы, с одной стороны, развитие сектора ИКТ экономики региона, а с другой - рост потребления цифровых продуктов и услуг бизнесом вне сектора ИКТ, населением и организациями бюджетной сферы региона (здравоохранением, образованием, социальной защитой).

Для активизации развития сектора ИКТ экономики региона требуется разработка и реализация системы мер государственной поддержки, сфокусированных на нескольких направлениях:
1) кадровое обеспечение региональной экономики специалистами, обладающими ИТ-навыками;

2) осуществление НИОКР по тематике сквозных цифровых технологий и внедрение результатов НИОКР, разработка на этой основе новых продуктов и услуг сектором ИКТ;

3) расширение использования продуктов и услуг сектора ИКТ во всех отраслях экономики региона, включая бюджетную сферу (увеличение затрат на ИКТ), за счёт всех источников (бюджет, внебюджетные источники);

4) развитие инфраструктуры доступа населения к мобильному Интернету и Интернету на основе широкополосного доступа.

Кадровое обеспечение сектора ИКТ является, на наш взгляд, наиболее сложной задачей. Это связано, с одной стороны, с длительным циклом подготовки соответствующих специалистов системами среднего профессионального образования (СПО) и высшего образования (BO). Так, срок обучения в системе СПО составляет от 1 года до 4 лет, в системе ВО от 4 до 6,5 лет. С другой стороны, образовательные программы СПО и ВО слабо увязаны с потребностями работодателей с точки зрения формирования наиболее актуальных компетенций выпускников. Исходя из этого, необходимо развитие дополнительного профессионального образования (ДПО) по запросам рынка труда сектора ИКТ экономики регионов, а также совершенствование основного среднего и высшего образования в направлении формирования наиболее актуальных ИТ-компетенций выпускников.

Изучение передового зарубежного опыта показало, что во всех развитых странах большая роль отводится государственному заказу на проведение НИОКР, который фактически создает новый рынок для производителей сектора ИКТ. Широкая практика тематически ориентированного государственного финансирования (конкурсно-контрактного) выполнения НИОКР по тематикам сквозных цифровых технологий должна осуществляться и в регионах России. 
В странах - лидерах научнотехнического развития созданы системы мер государственной политики стимулирования бизнеса к осуществлению расходов на НИОКР косвенными методами - путём создания для предприятий, осуществляющих эти расходы, различных налоговых и неналоговых стимулов. Благодаря этому инвестиции в НИОКР для частного сектора являются прибыльными. Развивающиеся страны, которые стремятся догнать лидеров научно-технического развития, применяют ещё более льготные меры стимулирования бизнеса к осуществлению расходов на НИОКР.

Таким образом, на уровне региона требуется осуществление следующих мер государственного стимулирования:

- увеличение государственного заказа на подготовку кадров, обладающих ИТ-компетенциями в системе СПО;

- формирование регионального госзаказа организациям высшего образования на программы ДПО, содержание которых отвечает требованиям работодателей сектора ИКТ экономики региона;

- грантовое финансирование НИОКР по тематикам сквозных цифровых технологий за счет консолидированного бюджета региона;

- для научных организаций и учреждений высшего образования - финансовая поддержка коммерциализации результатов исследований и разработок в области цифровой экономики (компенсация части затрат на получение патентов, выставочно-ярмарочную деятельность, субсидирование части процентных ставок по кредитам и проч.) за счет средств консолидированного бюджета региона;

- налоговые и неналоговые льготы для предприятий региона, осуществляющих заказ на НИОКР организациям высшего образования и научным организациям;

- налоговые и неналоговые льготы промышленным предприятиям, осуществляющим внедрение «интернета вещей» на свои производственные объекты;

- увеличение расходов консолидированного бюджета региона на разработку и внедрение информационных систем в органах государственного управления, органах местного самоуправления, здравоохранении, образовании, органах социальной защиты.

Внедрение результатов НИОКР предприятиями сектора ИКТ и разработка ими на этой основе новых продуктов и услуг на базе сквозных цифровых технологий требуют улучшения их доступа к инвестициям, в т. ч. заёмным. Использование продуктов и услуг сектора ИКТ во всех отраслях экономики, включая бюджетную сферу, также требует значительных инвестиций. Следовательно, необходимо улучшение доступа к инвестициям для предприятий всех отраслей экономики, при закупке ими отечественных продуктов и услуг сектора ИКТ.

Развитие инфраструктуры доступа населения к мобильному и широкополосному Интернету является необходимым условием, обеспечивающим возможность потребления населением регионов России продуктов и услуг цифровой экономики. Это требует реализации мер государственной поддержки в отношении инфраструктурных проектов в этой сфере.

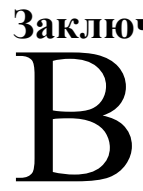
чение экономической литературе выделяют несколько разновидностей направляемого государством развития экономики трансформацию, модификацию, модернизацию. Наиболее масштабную форму из них имеет трансформация, которая предполагает кардинальное преобразование сложившейся экономической системы.

Цифровая трансформация экономики - это процесс интеграции ИКТ во все экономические процессы, требующий внесения принципиальных изменений в производство как существующих, так и создания новых продуктов и услуг, их распределение, обмен и потребление, изменяющий качественные характеристики экономической системы. Иными словами, цифровая трансформация экономики - это не просто процесс внедрения ИКТ, а качественно иное состояние - интеграция, 
встраивание ИКТ в экономические процессы.

При этом цифровая трансформация экономики, в силу масштабности, должна осуществляться именно как процесс, управляемый органами государственной власти на всех уровнях - федеральном, региональном, местном. Без направляющего воздействия со стороны органов государственной власти, как нам представляется, цифровая трансформация не будет успешной.

Из авторского определения цифровой трансформации следует особая роль сектора ИКТ в развитии экономики. Так, в современной экономической науке сформировался устойчивый постулат о прямом положительном влиянии ИКТ на экономическое развитие. В этой связи возникает гипотеза о необходимости государственного воздействия на факторы, оказывающие влияние на развитие сектора ИКТ, для последующего обеспечения цифровой трансформации экономики. В настоящем исследовании для выявления факторов, определяющих развитие ИКТ, применялся инструментарий эконометрического моделирования.

Считаем необходимым в качестве зависимых (управляемых) переменных моделей использовать три показателя, в наибольшей степени характеризующих развитие сектора ИКТ экономики региона: «численность занятых в секторе ИКТ», «объем отгруженных товаров собственного производства, выполненных работ, услуг собственными силами организаций сектора ИКТ» и «затраты на ИКТ».

Методологической основой для отбора факторов, влияющих на указанные нами зависимые переменные, стал подход, используемый международной организацией International Telecommunication Union для оценки индекса развития ИКТ (IDI).

Построенные эконометрические модели показывают высокую значимость в развитии сектора ИКТ факторов, связанных с цифровизацией образования как в общеобразовательных организациях, так и в организациях среднего профессионального и высшего образования.

Исходя из этого, сфокусированное воздействие органов государственной власти региона на сферы общего образования, среднего профессионального и высшего образования региона сможет обеспечить более успешную цифровую трансформацию региональной экономической системы. Это предопределяет необходимость разработки системы мер государственного воздействия на данные сферы, как в части подготовки кадров, так и в части осуществления НИОКР, что составляет перспективы приоритетного научного исследования авторов.

\section{Список литературы}

1. Шелегеда Б.Г., Шарнопольская О.Н., Погоржельская Н.В. Методологические подходы к исследованию структурных трансформаций в развитии экономических систем // Вестник Пермского университета. Серия «Экономика». 2017. Т. 12, № 2. С. 172-188. doi: 10.17072/19949960-2017-2-172-188.

2. Норт Д. Институты, институциональные изменения и функционирование экономики / пер. с англ. А.Н. Нестеренко; предисл. и науч. ред. Б.З. Мильнера. М.: Фонд экономической книги «Начала», 1997. $108 \mathrm{c.}$

3. Слива С.В. Направляемое развитие экономики: приемы, эволюция, эффективность // Вестник Южно-Уральского государственного университета. Серия: Экономика и менеджмент. 2015. T. 9, № 3. C. 34-40. doi: 10.14529/em090304.

4. Кейнс Дж.М. Общая теория занятости, процента и денег / пер. с англ.; под ред. А.Г. Милейковского и И.М. Осадчей. М.: Прогресс, 1978. 1650 с.

5. Иванов В.В., Малинеикий Г.Г. Цифровая экономика: от теории к практике // Инновации. 2017. T. 12 (230). C. 3-12.

6. Тамбовиев В.Л. Государственное регулирование государства: вопросы теории, международный опыт, российские реформы. М.: Российско-Европейский центр экономической политики, 2004. 36 с. 
7. Баранов И.Н. Новый государственный менеджмент: эволюция теории и практики применения // Российский журнал менеджмента. 2012. Т. 1, № 1. С. 51-64.

8. Акаткин И.Л., Ясиновская Е.Д. Цифровая трансформация государственного управления: Датацентричность и семантическая интероперабельность. M.: URSS, 2019. 724 с.

9. Смотрицкая И.И., ЧерныхС.И. Современные тенденции цифровой трансформации государственного управления // Вестник Института экономики Российской академии наук. 2018. № 5. C. 22-36.

10. Якунин В.И., Сулакшин С.С., Вилисов М.В., Кушлин В.И. О модернизации государственной системы управления экономическим развитием в России. М.: Научный эксперт, 2008. 104 с.

11. Карпунина E.K. Трансформация как способ развития экономической системы // Вестник Тамбовского университета. Серия: Гуманитарные науки. 2011. Вып. 4 (96). С. 27-35.

12. Solow R.M. We'd better watch out // New York Times Book Review. New York, July 1987. $36 \mathrm{p}$.

13. Скрипкин К.Г., Тесленко М.А. Парадокс производительности и человеческий капитал // Региональное развитие: стратегии и человеческий капитал: в 2 т.: материалы междунар. науч.-практ. конф., г. Екатеринбург, 10-11 апреля 2014 г. Екатеринбург: Изд-во Урал. ун-та, 2014. Т. 1. С. 241-251.

14. Wiel H. van der. Does ICT boost Dutch productivity growth? 2001. URL: https://ideas.repec. org/p/cpb/docmnt/16.rdf.html (дата обращения: 22.08.2019).

15. Pohjola M. New economy in growth and development // Oxford Review of Economic Policy. 2002. Vol. 18, Iss. 3. P. 380-396.

16. Khuong V.M.M. ICT as a source of economic growth in the information age: Empirical evidence from the 1996-2005 period // Telecommunications Policy. 2011. Vol. 35, № 4. P. 357-372.

17. RodriguezJ., Martinez D. The role of ICT in the economic growth and productivity of Andalusia // JRC Scientific and Technical Reports, 2007. 52 p. URL: https://publications.jrc.ec.europa.eu/ repository/ bitstream/JRC37310/eur22781en.pdf (дата обращения: 23.08.2019).

18. Кастельс М. Информационная эпоха: экономика, общество и культура / пер. с англ.; под науч. ред. О.И. Шкаратана. М.: Изд. дом ГУ-ВШЭ, 2000. 608 с.

19. Глазьев С.Ю. Великая цифровая экономика // Изборский клуб, 2017. URL: https://izborskclub.ru/14013 (дата обращения: 25.08.2019).

20. Кузнецов Ю.А., Перова В.И., Семиков Д.С. Информационные и коммуникационные технологии как фактор развития цифровой экономики в Российской Федерации // Вестник Нижегородского университета им. Н.И. Лобачевского. Серия: Социальные науки. 2017. № 4 (48). C. 38-47.

21. Юрьева А.А. ИКТ в социально-экономическом развитии региона: постановка вопроса // Международный научно-исследовательский журнал. 2012. № 1. С. 12-16.

22. Скуфьина Т.П. Региональное развитие России в контексте макроэкономических движений / Российская акад. наук, Кольский науч. центр, Ин-т экономических проблем им. Г.П. Лузина. Апатиты: КНЦ РАН, 2016. 126 с.

23. Баранов С.В., Скуфьина Т.П. Информационно-коммуникационные технологии и экономическое развитие регионов России: поиск зависимостей и перспективных направлений регулирования // Вопросы статистики. 2014. № 5. С. 41-53.

24. Миролюбова Т.В., Карлина Т.В., Николаев Р.С. Цифровая экономика: проблемы идентификации и измерений в региональной экономике // Экономика региона. 2020. Т. 16, вып. 2. C. 377-390.

25. Baltagi B.H. Econometric analysis of panel data. Chichester: John Wiley \& Sons, 1995. 338 p.

26. Deaton A. Panel data from series of cross-sections // Journal of Econometrics. 1985. Vol. 30. P. 109-126.

27. Ратникова T.A. Введение в эконометрический анализ панельных данных // Экономический журнал ВШЭ. 2006. № 4. С. 638-669.

28. Wooldridge J.M. Econometric analysis of cross section and panel data. 2nd ed. N. Y.: John Wiley \& Sons, 2007. 1097 p.

29. Fuller W.A., Battese G.E. Estimation of linear models with cross-error structure // Journal of Econometrics. 1974. Vol. 2. P. 128-134. 


\section{Сведения об авторах}

Миролюбова Татьяна Васильевна - доктор экономических наук, профессор, заведующая кафедрой мировой и региональной экономики, экономической теории, Пермский государственный национальный исследовательский университет (614990, Россия, г. Пермь, ул. Букирева, 15; e-mail: mirolubov@list.ru).

Радионова Марина Владимировна - кандидат физико-математических наук, доцент, доцент кафедры информационных систем и математических методов в экономике, Пермский государственный национальный исследовательский университет (614990, Россия, г. Пермь, ул. Букирева, 15; e-mail: m.radionova812@gmail.com).

\section{References}

1. Shelegeda B.G., Sharnopol'skaya O.N., Pogorzhel'skaya N.V. Metodologicheskie podkhody $\mathrm{k}$ issledovaniyu strukturnykh transformatsii $\mathrm{v}$ razvitii ekonomicheskikh system [Methodological approaches to the study of structural transformation in the development of economic systems]. Vestnik Permskogo universiteta. Seriya «Ekonomika» [Perm University Herald. Economy], 2017, vol. 12, no. 2, pp. 172-188. (In Russian). doi: 10.17072/1994-9960-2017-2-172-188.

2. North D. Instituty, institutsional'nye izmeneniya i funktsionirovanie ekonomiki. Per. s angl. A.N. Nesterenko; predisl. i nauch. red. B.Z. Mil'nera [Institutes, institutional change and economic performance. Trans. from English by A.N. Nesterenko; introduction and ed. by B.Z. Milner]. Moscow, Fond ekonomicheskoi knigi «Nachala» Publ., 1997. 108 p. (In Russian).

3. Sliva S.V. Napravlyaemoe razvitie ekonomiki: priemy, evolyutsiya, effektivnost' [Direct economic development: methods, evolution, efficiency]. Vestnik Yuzhno-Ural'skogo gosudarstvennogo universiteta. Seriya: Ekonomika $i$ menedzhment [Bulletin of the South Ural State University. Ser. Economics and Management], 2015, vol. 9, no. 3, pp. 34-40. (In Russian). doi: 10.14529/em090304.

4. Keynes J.M. Obshchaya teoriya zanyatosti, protsenta $i$ deneg. Per. s angl. pod red. A.G. Mileikovskogo i I.M. Osadchei [The general theory of employment, interest and money. Transl. from English and ed. by A.G. Mileikosvkii and I.M. Osadchaya]. Moscow, Progress Publ., 1978. 1650 p. (In Russian).

5. Ivanov V.V., Malinetskii G.G. Tsifrovaya ekonomika: ot teorii k praktike [Digital economy: From theory to practice]. Innovatsii [Innovations], 2017, vol. 12 (230), pp. 3-12. (In Russian).

6. Tambovtsev V.L. Gosudarstvennoe regulirovanie gosudarstva: voprosy teorii, mezhdunarodnyi opyt, rossiiskie reformy [Public regulation of the state: Issues of theory, international experience, Russian reforms]. Moscow, Rossiisko-Evropeiskii tsentr ekonomicheskoi politiki Publ., 2004. 36 p. (In Russian).

7. Baranov I.N. Novyi gosudarstvennyi menedzhment: evolyutsiya teorii i praktiki primeneniya [New public management: An evolution of theory and implementation]. Rossiiskii zhurnal menedzhmenta [Russian Management Journal], 2012, vol. 1, no. 1, pp. 51-64. (In Russian).

8. Akatkin I.L., Yasinovskaya E.D. Tsifrovaya transformatsiya gosudarstvennogo upravleniya: Datatsentrichnost' $i$ semanticheskaya interoperabel'nost' [Digital transformation of public governance: data centricity and semantic interoperability]. Moscow, URSS Publ., 2019. 724 p. (In Russian).

9. Smotritskaya I.I., Chernykh S.I. Sovremennye tendentsii tsifrovoi transformatsii gosudarstvennogo upravleniya [Modern trends in the digital transformation of public administration]. Vestnik Instituta ekonomiki Rossiiskoi akademii nauk [The Bulletin of the Institute of Economics of the Russian Academy of Sciences], 2018, no. 5, pp. 22-36. (In Russian).

10. Yakunin V.I., Sulakshin S.S., Vilisov M.V., Kushlin V.I. O modernizatsii gosudarstvennoi sistemy upravleniya ekonomicheskim razvitiem $v$ Rossii [On modernization of the public governance system for the economic development in Russia]. Moscow, Nauchnyi ekspert Publ., 2008. 104 p. (In Russian).

11. Karpunina E.K. Transformatsiya kak sposob razvitiya ekonomicheskoi sistemy [Transformation as a way of economical system development]. Vestnik Tambovskogo universiteta. Seriya: Gumanitarnye nauki [Tambov University Review. Series: Humanities], 2011, iss. 4 (96), pp. 27-35. (In Russian).

12. Solow R.M. We'd better watch out. New York Times Book Review. New York, July 1987. 36 p.

13. Skripkin K.G., Teslenko M.A. Paradoks proizvoditel'nosti i chelovecheskii kapital [Paradox of productivity and human capital]. Regional'noe razvitie: strategii i chelovecheskii kapital: materialy 
mezhdunarodnoi nauchno-prakticheskoi konferentsii, g. Ekaterinburg, 10-11 aprelya 2014 g., v 2-kh . T. 1 [Regional Development: Strategies and Human Capital: Proceedings of the International Scientific and Practical Conference. Yekaterinburg, 10-11 April 2014, in 2 vol. Vol. 1]. Yekaterinburg, Izd-vo Ural. un-ta Publ., 2014, pp. 241-251. (In Russian).

14. van der Wiel H. Does ICT boost Dutch productivity growth? 2001. Available at: https://ideas.repec.org/p/cpb/docmnt/16.rdf.html (accessed 22.08.2019).

15. Pohjola M. New economy in growth and development. Oxford Review of Economic Policy, 2002, vol. 18, iss. 3, pp. 380-396.

16. Khuong V.M.M. ICT as a source of economic growth in the information age: Empirical evidence from the 1996-2005 period. Telecommunications Policy, 2011, vol. 35, no. 4, pp. 357-372.

17. Rodriguez J., Martinez D. The role of ICT in the economic growth and productivity of Andalusia. JRC Scientific and Technical Reports, 2007. 52 p. Available at: https://publications.jrc.ec.europa.eu/ repository/bitstream/JRC37310/eur22781en.pdf (accessed 23.08.2019).

18. Castells M. Informatsionnaya epokha: ekonomika, obshchestvo i kul'tura. Per. s angl.; pod nauch. red. O.I. Shkaratana [The information age: Economy, society and culture. Transl. from English, ed. by O.I. Shkaratan]. Moscow, Izd. dom GU-VShE Publ., 2000. 608 p.

19. Glaz'ev S.Yu. Velikaya tsifrovaya ekonomika [Great digital economy]. Izborskii klub [Izbor Club], 2017. Available at: https://izborsk-club.ru/14013 (accessed 25.08.2019).

20. Kuznetsov Yu.A., Perova V.I., Semikov D.S. Informatsionnye i kommunikatsionnye tekhnologii kak faktor razvitiya tsifrovoi ekonomiki $\mathrm{v}$ Rossiiskoi Federatsii [Information and communication technologies as a factor in the development of digital economy in the Russian Federation]. Vestnik Nizhegorodskogo universiteta im. N.I. Lobachevskogo. Seriya: Sotsial'nye nauki [Vestnik of Lobachevsky State University of Nizhni Novgorod. Series: Social sciences], 2017, no. 4 (48), pp. 38-47. (In Russian).

21. Yur'eva A.A. IKT v sotsial'no-ekonomicheskom razvitii regiona: postanovka voprosa [ICT in the social and economic development of a region: Statement of a question]. Mezhdunarodnyi nauchnoissledovatel'skii zhurnal [International Research Journal], 2012, no. 1, pp. 12-16. (In Russian).

22. Skuf'ina T.P. Regional'noe razvitie Rossii $v$ kontekste makroekonomicheskikh dvizhenii. Rossiiskaya akad. nauk, Kol'skii nauch. tsentr, In-t ekonomicheskikh problem im. G.P. Luzina [Regional development of Russia in the context of macroeconomic movements. Russian Academy of Sciences. Kola Science Centre. G.P. Luzin Institute for economic studies]. Apatity, KNTs RAN Publ., 2016. 126 p. (In Russian).

23. Baranov S.V., Skuf'ina T.P. Informatsionno-kommunikatsionnye tekhnologii i ekonomicheskoe razvitie regionov Rossii: poisk zavisimostei i perspektivnykh napravlenii regulirovaniya [Information and communication technology and economic development of regions of the Russian Federation: Search for dependencies and promising lines of regulation]. Voprosy statistiki [Issues of Statistics], 2014, no. 5, pp. 41-53. (In Russian).

24. Mirolyubova T.V., Karlina T.V., Nikolaev R.S. Tsifrovaya ekonomika: problemy identifikatsii i izmerenii v regional'noi ekonomike [Digital economy: Identification and measurements problems]. Ekonomika regiona [Economy of region], 2020, vol.16, iss. 2, pp. 377-390.

25. Baltagi B.H. Econometric analysis of panel data. Chichester, John Wiley \& Sons, 1995. 338 p.

26. Deaton A. Panel data from series of cross-sections. Journal of Econometrics, 1985, vol. 30, pp. 109-126.

27. Ratnikova T.A. Vvedenie $\mathrm{v}$ ekonometricheskii analiz panel'nykh dannykh [Introduction to econometric analysis of panel data]. Ekonomicheskii zhurnal VShE [Higher School of Economics Economic Journal], 2006, no. 4, pp. 638-669. (In Russian).

28. Wooldridge J.M. Econometric analysis of cross section and panel data. 2nd ed. New York, John Wiley \& Sons, 2007. 1097 p.

29. Fuller W.A., Battese G.E. Estimation of linear models with cross-error structure. Journal of Econometrics, 1974, vol. 2, pp. 128-134. 


\section{Information about the Authors}

Miroliubova Tatyana Vasil'evna - Doctor of Economic Sciences, Professor, Head of the Department of Global and Regional Economy, Economic Theory, Perm State University (15, Bukireva st., Perm, 614990, Russia; e-mail: mirolubov@list.ru).

Radionova Marina Vladimirovna - Candidate of Physics and Mathematics, Associate Professor, Assistant Professor at the Department of Information Systems and Mathematical Methods in Economics, Perm State University (15, Bukireva st., Perm, 614990, Russia; e-mail: m.radionova812@ gmail.com).

\footnotetext{
Просьба ссылаться на эту статью в русскоязычных источниках следующим образом: Миролюбова T.B., Радионова М.B. Роль сектора ИКТ и факторы цифровой трансформации региональной экономики в контексте государственного управления // Вестник Пермского университета. Сер. «Экономика». 2020. Том 15. № 2. С. 253-270. doi: 10.17072/1994-9960-2020-2-253-270
}

\section{Please cite this article in English as:}

Miroliubova T.V., Radionova M.V. ICT sector role and digital transformation factors in the regional economy in the context of public governance. Perm University Herald. Economy, 2020, vol. 15, no. 2, pp. 253-270. doi: 10.17072/1994-9960-2020-2-253-270 